\title{
Faktor Risiko Burnout pada Petugas di Instalasi Rekam Medis dan Informasi Kesehatan RSUD K.R.M.T Wongsonegoro
}

\author{
The Risk Factors of Burnout on Medical Record and Health Information \\ Installation Officers at K.R.M.T Wongsonegoro Public Hospital
}

\author{
Zefan Adiputra Golo ${ }^{1}$ \\ Eliyah $^{2}$ \\ Eiska Rohmania Zein ${ }^{3}$
}
1) Jurusan Rekam Medis dan Informasi Kesehatan Poltekkes Kemenkes Semarang Jl. Tirto Agung, Pedalangan, Banyumanik, Semarang
2) Jurusan Rekam Medis dan Informasi Kesehatan Poltekkes Kemenkes Semarang
Jl. Tirto Agung, Pedalangan, Banyumanik, Semarang
3) Jurusan Rekam Medis dan Informasi Kesehatan Poltekkes Kemenkes Semarang
Jl. Tirto Agung, Pedalangan, Banyumanik, Semarang
E-mail:zefanadiputra91@gmail.com

\begin{abstract}
Burnout is a state of exhaustion both physically, mentally, and emotionally. A preliminary study conducted at the Medical Record and Health Information Installation at RSUD K.R.MT Wongsonegoro found burnout symptoms in officers which were marked by complaints that employees felt physical, mental and emotional fatigue at work for the past year. The aim of this study was to determine the risk factors for burnout in officers at the Medical Record and Health Information Installation seen from demographic factors. The research method uses an analytical survey with a cross-sectional design. The research instrument was adopted from the Maslach Burnout Inventory (MBI). Data analysis using Kendall's tau test and Simple Linear Regression test. The results of the study found that the burnout rate for medical record and health information officers was in the high category of $52.6 \%$. The results of the correlation test showed that of the six demographic factors, only age and work period had a significant relationship with burnout levels in medical record officers $(p<0.05)$. The results of the simple linear regression test showed that the significance value of the age factor was 0.029 and the significance value of the work period factor was 0.049, so it can be concluded that these two factors have a significant effect on burnout.
\end{abstract}

Keywords: Burnout, Risk Factor, Medical Record Officer, Health Information

\begin{abstract}
Abstrak
Burnout merupakan kondisi kelelahan baik secara fisik, mental maupun emosional. Studi pendahuluan yang dilakukan di Instalasi Rekam Medis dan informasi kesehatan RSUD K.R.MT Wongsonegoro menemukan gejala burnout pada petugas yang ditandai dengan adanya keluhan pegawai merasakan kelelahan fisik, mental dan emosional dalam pekerjaan selama satu tahun terakhir. Tujuan penelitian ini mengetahui faktor risiko burnout pada petugas di Instalasi Rekam Medis dan Informasi Kesehatan dilihat dari faktor demografik. Metode penelitian meenggunakan survey analitik dengan desain cross-sectional. Instrument penelitian diadopsi dari Maslach Burnout Inventory (MBI). Analisis data menggunakan uji Kendall's tau dan uji Regresi Linier Sederhana. Hasil penelitian menemukan tingkat burnout pada petugas rekam medis dan informasi kesehatan berada pada kategori tinggi sebesar 52,6\%. Hasil uji korelasi menunjukkan dari ke enam faktor demografik, hanya faktor umur dan masa kerja yang memiliki hubungan yang signifikan dengan tingkat burnout pada petugas rekam medis $(p<0.05)$. Hasil uji regresi linear sederhana menunjukkan nilai signifikansi faktor umur 0.029 dan nilai signifikansi faktor masa kerja 0.049, sehingga dapat disimpulkan kedua faktor tersebut berpengaruh signifikan terhadap burnout.
\end{abstract}

Kata kunci: Burnout, Faktor Risiko, Petugas Rekam Medis, Informasi Kesehatan 


\section{A. Pendahuluan}

Sumber daya manusia yang bekerja di unit rekam medis dan informasi kesehatan tidak secara langsung terlibat dalam pelayanan klinis pasien. Namun kegiatan pelayanan di unit kerja ini merupakan bagian penting yang mendukung keberlangsungan proses pelayanan di rumah sakit. Tuntutan tugas dan tanggungjawab yang tinggi, serta beban pekerjaan yang semakin lama semakin bertambah akibat jumlah kunjungan pasien yang terus meningkat, secara langsung akan berdampak pada kondisi kelelahan fisik dan mental petugas di unit rekam medis dan informasi kesehatan.

Kelelahan fisik dan mental sebagai dampak dari beban kerja merupakan faktor yang dapat menimbulkan burnout (Xiaoming et al., 2014). World Health Organization (WHO) memasukan burnout sebagai diagnostik tambahan dalam International Statistical Classification of Disease and Related Health Problems dengan kode diagnosis ICD Z73.0 yang didefinisikan sebagai kondisi "Burn-out". Maslach \& Jackson mendefinisikan burnout sebagai akibat dari stress berkepanjangan di tempat kerja yang ditandai dengan kelelahan emosional, depersonalisasi, dan ketidakpuasan pada prestasi (Nowacka et al., 2018).

Menurut Reith (2018), fenomena burnout pada tenaga kesehatan bukanlah merupakan hal yang baru. Burnout telah dirasakan oleh setiap profesional kesehatan yang bekerja di organisasi pelayanan kesehatan. Lima profesi kesehatan dengan prevalensi burnout dari yang tertinggi ke rendah di rumah sakit adalah perawat $(66 \%)$, asisten dokter $(61 \%)$, dokter $(38,6 \%)$, staf administrasi $(36,1 \%)$ dan teknisi medis $(31,9 \%)$ (Chou et al., 2014).

Burnout pada tenaga kesehatan di rumah sakit perlu menjadi perhatian bagi manajemen rumah sakit, hal ini dikarenakan burnout tidak hanya dapat dialami oleh tenaga medis seperti dokter dan perawat, namun dapat pula terjadi pada tenaga non medis seperti pada petugas di unit rekam medis dan informasi kesehatan.

Instalasi Rekam Medis di RSUD K.R.M.T Wongsonegoro Semarang merupakan unit penunjang palayanan yang terdiri dari empat bagian yaitu : penerimaan pasien (TPPRI/TPPRJ), pengelolaan dokumen, filling dan pelaporan. Berdasarkan studi pendahuluan didapatkan data bahwa dari 20 orang petugas di instalasi rekam medis yang diwawancarai, menyatakan mereka pernah merasakan kelelahan secara fisik maupun mental dalam pekerjaan selama satu tahun terakhir.

Dari hasil wawancara tersebut, peneliti melihat adanya gejala burnout pada petugas di Instalasi Rekam Medis. Pernyataan peneliti ini berdasarkan pada pernyataan dari Schaufeli et al. (2009) bahwa burnout merupakan sindrom yang berhubungan dengan pekerjaan yang ditandai dengan tingkat kelelahan yang berlebihan baik secara fisik, mental maupun emosional.

Patel et al. (2018) menyatakan bahwa burnout dapat dipengaruhi oleh beberapa faktor, yaitu faktor demografik (jenis kelamin, umur, pendidikan, lama bekerja dan status pernikahan), faktor personal (stress kerja, beban kerja dan tipe kepribadian) dan faktor organisasi (kondisi kerja dan dukungan sosial).

Tujuan penelitian ini adalah mengetahui faktor risiko burnout pada petugas di Instalasi Rekam Medis dan Informasi Kesehatan RSUD Wongsonegoro dilihat dari faktor demografik petugas.

\section{B. Metode}

Penelitian ini merupakan penelitian survey analitik dengan desain cross-sectional. Instrument penelitian yang digunakan adalah kuesioner yang diadopsi dari kuesioner Maslach Burnout Inventory (MBI). Populasi dalam penelitian ini adalah seluruh petugas di Instalasi Rekam 
Medis dan Informasi Kesehatan sejumlah 57 orang. Teknik penarikan sampel menggunakan total sampling, dimana sampel penelitian sama dengan jumlah populasi. Analisis data menggunakan uji regresi linier sederhana dan diolah menggunakan software Statistical Package for Social Science (SPSS) V.22.

\section{Hasil dan Pembahasan}

Adapun karakteristik responden pada penelitian ini dapat dlihat pada tabel berikut :

Tabel 1. Distribusi Karakteristik Responden

\begin{tabular}{|c|c|c|}
\hline Karakteristik & $\mathrm{f}$ & $\%$ \\
\hline \multicolumn{3}{|l|}{ Jenis Kelamin } \\
\hline Laki-Laki & 19 & 26,7 \\
\hline Perempuan & 38 & 66,7 \\
\hline \multicolumn{3}{|l|}{ Umur } \\
\hline 21-30 Tahun & 26 & 45,6 \\
\hline 31-40 Tahun & 15 & 26,3 \\
\hline 41-50 Tahun & 8 & 14,0 \\
\hline$>50$ Tahun & 8 & 14,0 \\
\hline \multicolumn{3}{|c|}{ Status Perkawinan } \\
\hline Menikah & 42 & 73,7 \\
\hline Belum Menikah & 15 & 26,3 \\
\hline \multicolumn{3}{|c|}{ Tingkat Pendidikan } \\
\hline SMA & 8 & 14,0 \\
\hline D-III & 42 & 73,7 \\
\hline D-IV/S1 & 6 & 10,5 \\
\hline S2 & 1 & 1,8 \\
\hline \multicolumn{3}{|l|}{ Masa Kerja } \\
\hline 1-5 Tahun & 27 & 47,4 \\
\hline 6-10 Tahun & 9 & 15,8 \\
\hline$>10$ Tahun & 21 & 36,8 \\
\hline \multicolumn{3}{|c|}{ Status Kepegawaian } \\
\hline PNS & 21 & 36,8 \\
\hline Non-PNS & 36 & 63,2 \\
\hline
\end{tabular}

Berdasarkan tabel 1 di atas, dapat diketahui bahwa responden yang berjenis kelamin laki-laki sebanyak 19 orang (33,3\%) dan responden berjenis kelamin perempuan sebanyak 38 orang $(66,7 \%)$. Petugas yang menjadi responden paling banyak berumur 21-30 tahun $(45,6 \%)$. Status perkawinan dari responden lebih banyak telah menikah yaitu, 73,7\%. Tingkat pendidikan responden umumnya berada pada level Diploma 3 sebanyak 42 orang $(73,7 \%)$ dan paling rendah tingkat pendidikan S2 sebanyak 1 orang $(1,8 \%)$. Masa kerja dari petugas yang menjadi responden paling banyak berada pada masa kerja 1-5 tahun yaitu 27 orang $(47,4 \%)$ dan paling sedikit 6-10 tahun (15,8\%). Status kepegawaian dari petugas di Instalasi Rekam Medis dan Informasi Kesehatan lebih banyak berstatus Non-PNS yaitu, 63,2\%.

Hasil analisis tingkat burnout pada petugas di Instalasi Rekam Medis dan Informasi Kesehatan RSUD K.R.M.T Wongsonegoro adalah sebagai berikut :

Tabel 2. Tingkat Burnout pada Petugas di Instalasi Rekam Medis dan Informasi Kesehatan RSUD K.R.M.T Wongsonegoro

\begin{tabular}{lcc}
\hline \multicolumn{1}{c}{ Tingkat Burnout } & f & \% \\
\hline Tinggi & 30 & 52,6 \\
Rendah & 27 & 47,4 \\
Total & 57 & 100,0 \\
\hline
\end{tabular}

Dari tabel 2 dapat diketahui bahwa tingkat burnout pada petugas rekam medis dan informasi kesehatan berada pada kategori tinggi sebesar $52,6 \%$ dan berada pada kategori rendah sebesar $47,4 \%$.

Hasil uji korelasi menggunakan uji Kendall's tau untuk melihat hubungan antara variabel faktor demografik dengan burnout adalah sebagai berikut :

Tabel 3. Hubungan Faktor Demografik dengan Burnout pada Petugas

\begin{tabular}{lccc}
\hline \multicolumn{1}{c}{$\begin{array}{c}\text { Faktor } \\
\text { Demografik }\end{array}$} & $\mathbf{3}$ & $\begin{array}{c}\text { Pearson } \\
\text { Correlation }\end{array}$ & $\begin{array}{c}\text { Sig. } \\
\text { (2.tailed) }\end{array}$ \\
\cline { 2 - 4 } & & -145 & .197 \\
Jenis Kelamin & 57 & $-.225^{*}$ & .031 \\
Umur & 57 & .138 & .220 \\
$\begin{array}{l}\text { Status } \\
\text { Perkawinan }\end{array}$ & 57 & & \\
$\begin{array}{l}\text { Pendidikan } \\
\text { Terakhir }\end{array}$ & 57 & .133 & .219 \\
$\begin{array}{l}\text { Masa Kerja } \\
\text { Status }\end{array}$ & 57 & $-.238^{*}$ & .026 \\
Kepegawaian & 57 & .183 & .104 \\
\hline \multicolumn{1}{l}{ Berdark }
\end{tabular}

Berdasarkan tabel 3, dapat dilihat hasil uji korelasi menunjukkan bahwa dari ke enam faktor demografik, hanya faktor umur dan masa kerja yang memiliki 
hubungan yang signifikan dengan tingkat burnout pada petugas rekam medis ( $p<$ 0.05). Sedangkan faktor jenis kelamin, status perkawinan, pendidikan terakhir dan status kepegawaian tidak memiliki hubungan dengan burnout pada petugas.

Hasil uji regresi linear sederhana untuk melihat apakah ada pengaruh faktor umur dan masa kerja dengan burnout pada petugas adalah sebagai berikut:

Tabel 4 Hasil Uji Regresi Linear

\begin{tabular}{ccccc}
\hline \multicolumn{5}{c}{ Unstandardized } \\
Coefficients \\
Model & B & $\begin{array}{c}\text { Std. } \\
\text { Error }\end{array}$ & t & Sig. \\
\hline (Constant) & 37.672 & 1,748 & 21,55 & \multirow{2}{*}{029} \\
Umur & $-1,753$ &, 780 & $-2,24$ & \\
Constant) & 37.773 & 1,951 & 19,35 &, 049 \\
Masa Kerja & $-1,871$ &, 928 & $-2,01$ & \\
\hline
\end{tabular}

Berdasarkan pada tabel 4, dapat dilihat hasil uji regresi linear sederhana menunjukkan bahwa faktor umur memiliki pengaruh yang signifikan terhadap burnout pada petugas, hal ini ditunjukkan dengan nilai Sig. 0,029 $(<0,05)$. Selanjutnya faktor masa kerja juga memiliki pengaruh yang signifikan terhadap burnout pada petugas, hal ini ditunjukkan dengan nilai Sig. 0,049 (< $0,05)$.

Dari hasil penelitian ini ditemukan tingkat burnout pada petugas di Instalasi Rekam Medis dan Informasi Kesehatan cenderung berada pada kategori tinggi. Jika hal tersebut tidak cepat disadari oleh pimpinan unit dan pihak manajemen rumah sakit, maka akan berdampak pada kualitas pelayanan di unit kerja rekam medis. Menurut Asuero et al. (2014) kondisi burnout yang berkepanjangan pada profesional kesehatan akan mempengaruhi kinerja dan sikap profesional terhadap pasien.

Faktor umur dan masa kerja merupakan faktor risiko yang dapat membuat seorang petugas atau pegawai di Instalasi Rekam Medis dan Informasi Kesehatan mengalami kondisi burnout. Dari hasil penelitian ini diketahui rata-rata umur petugas paling banyak berada pada rentang umur 21-30 tahun dan 31-40 tahun.

Menurut Ang et al. (2016) dan Nowacka et al. (2018) faktor umur sebagai bagian dari sosio-demografik merupakan faktor yang signifkan mempengaruhi kelelahan kerja (burnout) yang tinggi pada perawat. Petugas yang berusia muda kemungkinan mengalami burnout lebih besar, hal ini dikarenakan pegawai yang berusia muda belum memiliki kematangan secara emosional dalam pekerjaan, sedangkan pegawai yang berusia tua telah mampu beradaptasi dengan pekerjaan mereka, sehingga mampu meminimalkan kemungkinan untuk mengalami burnout. Pernyataan ini didukung oleh penelitian dari Erickson \& Grove (2008) yang menemukan bahwa perawat yang berusia dibawah 30 tahun mengalami tingkat frustasi, kemarahan dan kelelahan yang lebih tinggi.

Masa kerja petugas juga menjadi faktor risiko yang mempengaruhi burnout pada petugas rekam medis dan informasi kesehatan. Hasil penelitian ini sejalan dengan penelitian yang dilakukan oleh Eliyana (2015) yang menemukan bahwa lama bekerja menjadi faktor yang berhubungan dengan burnout pada perawat pelaksana. Masa kerja petugas di Instalasi Rekam Medis dan Informasi Kesehatan RSUD Wongsonegoro paling banyak berada pada rentang masa kerja 1-5 tahun. Petugas yang memiliki masa kerja yang masih pendek cenderung akan mengalami kelelahan dikarenakan masih belum berpengalaman menghadapi tekanan dalam pekerjaan dan membutuhkan adaptasi dengan pekerjaan. Menurut Putri et al. (2019) kondisi burnout paling tinggi dialami oleh karyawan dengan masa kerja 0-5 tahun. Adapun karyawan dengan masa kerja lebih dari 10 tahun cenderung mengalami burnout pada pekerjaan dengan kategori rendah.

Meskipun hasil penelitian ini hanya menemukan faktor umur dan masa kerja yang menjadi faktor risiko burnout, namun kecenderungan burnout yang dialami oleh petugas di instalasi rekam medis dan 
informasi kesehatan secara langsung akan mempengaruhi kualitas pelayanan. Hal ini dikarenakan petugas yang mngalami burnout akan timbul perasaan negatif terhadap pekerjaan dan lingkungan kerjanya.

\section{Simpulan dan Saran}

Dari hasil penelitian dapat disimpulkan bahwa tingkat burnout pada petugas di unit rekam medis dan informasi kesehatan berada pada kateori tinggi. Hasil analisis menunjukkan bahwa faktor risiko burnout pada petugas dipengaruhi oleh faktor umur dan masa kerja petugas, sedangkan jenis kelamin, tingkat pendidikan, status perkawinan dan status kepegawaian tidak mempenaruhi burnout pada petugas.

Disarankan pada pimpinan unit kerja untuk menganalisis kembali standar beban kerja pegawai di setiap sub unit kerja, serta perlu menyusun data profil kepribadian setiap pegawai agar dapat digunakan untuk memonitoring kondisi pegawai dan merencanakan program pelatihan dan pengembangan yang sesuai kondisi dan kebutuhan pegawai. Diperlukan juga penelitian lebih lanjut untuk melihat faktor lain yang menjadi faktor risiko burnout pada petugas rekam medis dan informasi kesehatan.

\section{E. Ucapan Terima Kasih}

Peneliti mengucapkan terimakasih kepada Poltekkes Kemenkes Semarang, khususnya kepada Jurusan Rekam Medis dan Informasi Kesehatan yang telah mendukung penelitian ini.

\section{F. Daftar Pustaka}

Ang, Shin Y., Dhaliwal, Satvinder S., Ayre, Tracy C., Uthaman, T., Fong, Kuan Y., Tien, Choo E., Zhou, H., and Della, P. (2016). Demographics and Personality Factors Associated with Burnout among Nurses in a Singapore Tertiary Hospital. BioMed Research International.
Volume

2016.

https://doi.org/10.1155/2016/696 0184

Asuero, Andres M., Queralto, Jenny M., Pujol-Ribera, E., Berenguera, A., Rodriguez-Blanco, T., Epstein, R. M. (2014). Effectiveness of a mindfulness education program in Primary Health Care Professionals: A pragmatic controlled trial. Journal of Continuing Education in The Health Professions, 34(1), pp.4-12.

Chou, L. P., Li, C. Y., \& Hu. S. C. (2014). Job stress and burnout in hospital employess: Comparisons of different medical professions in a rgional hospital in Taiwan. BMJ Open, $\quad 4(2)$. https:// doi.org/10.1136/bmjopen2013-004185

Eliyana (2016). Faktor-faktor yang berhubungan dengan burnout perawat pelaksana di ruang rawat inap RSJ Provinsi Kalimantan Barat Tahun 2015. Jurnal ARSI, 2(3), pp.172-182.

Erickson, Rebecca J. and Grove, Wendy J. C. (2008). Why emotion matter: Age, agitation, and burnout among registered Nurses. The Online Journal of Issues $n$ Nursing, 13(1).

Nowacka, A., Piskorz, A., Wolfshaut-Wolak, R., Piatek, Jadwiga and Gniadek A. (2018). Selected socio-demographic and occupational factors of burnout syndrome in nurses employed in medical facilities in malopolska-preliminary resulst. International Journal of Enviromental Research and Public Health, 15(10). http://dx.doi.org/10.3390/ijerph15 $\underline{102083}$

Patel, R. S., Bachu, R., Adikey, A., Malik,M., and Shah, M. (2018). Behavioral sciences factor related to physician burnout and its consequences: A review. Journal Behavioral Sciences, 8(11).http://dx.doi.org/10.3390/bs $\underline{8110098}$ 
Putri, Lalitha A. Z., Zulkaida, Anita and Rosmasuri, Puti A. (2019) Perbedaan burnout pada karyawan ditinjau dari masa kerja. Jurnal Psikologi, $\quad$ 12(2), $\mathrm{pp}$ 157-165.https://doi.org/10.35760/ psi.2019.v12i2.2440

Reith, T. P. (2018). Burnout in United States Healthcare professionals: A narrative review. Cureus, 10(12), pp 1-9.

Scaufeli, Wilmar B., Leiter, Michael P. And Maslach C. (2009). Burnout: 35 years of research and practice. Internationa Journal of Career Management, $14(3)$. https://doi.org/10.1108/136204309
10966406

Xiaoming, Y., Ma, B. J., Chang, C. L., and Shieh, C. J. (2014). Effect of workload on burnout and turnover intention of medical staff: A study. Studies on Ethno-Medicine, 8(3), 229-237.

https://doi.org/10.31901/24566772. 2014/08.03.04 